\title{
Preparation of metallic bismuth by reduction of bismuth formates in ethylene glycol medium
}

\author{
Kseniya.V. Mishchenko-, Yurii.M. Yukhin \\ Institute of Solid State Chemistry and Mechanochemistry, SB RAS, 630128, Novosibirsk, Russia
}

\begin{abstract}
Nano - and microcrystalline bismuth metal powders consisting of spherical particles with a size of $150-250 \mathrm{~nm}$ were obtained by reducing bismuth formates in an ethylene glycol medium. The phase composition and morphology of the obtained reaction products were studied by X-ray phase and thermal analysis, differential scanning calorimetry, scanning and transmission electron microscopy. Using Uv-vis, it was shown that a bismuth-ethylene glycol complex is formed with an absorption maximum at $249 \mathrm{~nm}$ and an extinction coefficient of $5.7 \times 10^{3}\left(\mathrm{~L} \mathrm{~mol}^{-1} \mathrm{~cm}^{-1}\right)$ in a solution of chloric acid at $23^{\circ} \mathrm{C}$. The concentration of bismuth enhances to $0.018 \mathrm{~g} \mathrm{~L}^{-1}$ in the ethylene glycol medium with a gradual increase in the temperature to $60^{\circ} \mathrm{C}$ of the reaction mixture. Thermolysis of bismuth glycolate with a composition of $\mathrm{Bi}_{2}\left(\mathrm{OCH}_{2} \mathrm{CH}_{2} \mathrm{O}\right)_{3}$ is accompanied by the formation of metallic bismuth at $190^{\circ} \mathrm{C}$, which is oxidized to a monoclinic modification of bismuth oxide when the temperature increases in the air.
\end{abstract}

\section{Introduction}

Bismuth and its compounds are widely used in scientific researches and in practice. Due to its unique thermal and electrical properties, bismuth metal is a critical material in a variety of existing and potential technological applications. Bismuth is used in many fields, for example, in metallurgy as an additive to steels instead of toxic lead, or as a metal component of ceramics, in glasses, pigments, or lubricants [1]. In the electronic industry, bismuth particles are used in solder compositions or to create photo tools for the production of printed circuit boards [2]. Metallic bismuth as a semimetal with a set of unique properties, such as the magnetic resonance effect or thermoelectric properties, has a highly anisotropic Fermi surface, a low charge carrier density, a small effective mass, and a long free path [3-5]. The transition from the semimetal to the semiconductor occurs with decreasing grain size and associates with the quantum-size effect, which can be used in optical or electro-optical devices [6]. Despite the extensive use of bismuth in all these areas, the quantity of simple and reliable synthesis methods that can economically and expediently produce nano- or microsized bismuth particles is very limited [7-11]. Polyol synthesis is well known as a universal way for the production of fine metal particles [12, 13]. One of the methods for producing submicron-sized metals is the reduction of their organic or inorganic salts in an organic liquid medium with a high boiling point, for

— Corresponding author: mishenko.k@solid.nsc.ru 
example, ethylene glycol (EG), diethylene glycol, tetraethylene glycol, polyethylene glycol, or glycerin [13-16]. When using EG, the most likely reducing agent is glycolaldehyde [17], which is formed when EG is oxidized by air oxygen at $\mathrm{T}=170^{\circ} \mathrm{C}$ according to the reaction

$$
2 \mathrm{HOCH}_{2} \mathrm{CH}_{2} \mathrm{OH}+\mathrm{O}_{2} \rightarrow 2 \mathrm{HOCH}_{2} \mathrm{CHO}+2 \mathrm{H}_{2} \mathrm{O}
$$

According to [18], the amount of oxygen dissolved in the EG is a key factor controlling the reaction rate and the high yield of the target particles. It should be noted that the medium in which the process takes place is not only a reducing agent for the production of nanoparticles but also a stabilizer that restricts their growth in certain directions and prevents agglomeration. It is known $[19,20]$ that some stabilizers can selectively adsorb on certain faces, and sometimes they can be reducing agents of metal ions. The most common stabilizers of the nanoparticles are polyvinylpyrrolidone or sodium oleate [20,21]. However, the use of these compounds requires repeated washing of residues with non-polar organic solvents.

In this work, to reduce the temperature of synthesis bismuth formate $\mathrm{Bi}(\mathrm{HCOO})_{3}$ and bismuthite formate $(\mathrm{BiO}) \mathrm{HCOO}$, having low decomposition temperatures $\left(210-220^{\circ} \mathrm{C}\right)$, were used as initial precursors. A reduction of bismuth from formates was carried out in an EG medium (without stabilizing agents) in the temperature range of $100-190^{\circ} \mathrm{C}$. In this case, the EG uses as a reducing agent and a reaction medium.

\section{Experimental}

Bismuth oxide of special purity pure grade (TU 6-09-1853-77) formic acid (GOST 584873), and ethylene glycol of chemically pure grade (YU 2632-143-44493179-11) were used in the experiments without further purification. Solutions were prepared using distilled water.

The crystalline structures of the samples were characterized by X-ray powder diffraction (XRD, Bruker D8 Advance), with a CuK $\alpha$ radiation $(\mathrm{k}=1.5418 \AA)$. The thermal analysis (TA) was made by synchronous thermal analyzer STA 449 F1 Jupiter (NETZSCH $\mathrm{GmbX})$ in $\mathrm{Ar} / \mathrm{O}_{2}(80 / 20 \%)$ with a heating rate of $10 \% \mathrm{~min}$, conjugating with quadrupole mass spectrometer QMS 403C Aeolos. The following masses were registered: $m / e=18$ $\mathrm{H}_{2} \mathrm{O}^{+}, 44 \mathrm{CO}_{2}^{+}$. The morphology observation was performed on scanning electron microscope (SEM, Hitachi TM1000). High-resolution TEM images were obtained on a JEM-2010 microscope operated at $200 \mathrm{kV}$ (HRTEM, JEOL). The infrared spectra were run on an Infralum FT 801 (IR-spectroscopy, Lumex-Siberia) spectrophotometer. The sample, prepared as $\mathrm{KBr}$ disc, was examined within the range $400-4000 \mathrm{~cm}^{-1}$ to identify the functional groups. The uv-vis spectra of the liquid phase obtained at room temperature were recorded in the range of $180-700 \mathrm{~nm}$ with a $1 \mathrm{~cm}$ thick cuvette on a SPECS SSP 700 fluorescence Spectrophotometer (Spectroscopic Systems).

\section{Results and discussion}

Studies on the reduction of bismuth formates have shown that they were reduced to metal in the EG $\left(\mathrm{T}=197^{\circ} \mathrm{C}\right)$ at a temperature of $190-195^{\circ} \mathrm{C}$. The X-ray analysis of the reaction products (Fig. 1) obtained during the heat treatment of bismuth formates in the EG shows that the reduction process leads to formation of metallic bismuth and an intermediate compound. 




Fig. 1. XRD patterns of the as-synthesized (BiO)HCOO (1), treated with $\mathrm{EG}$ at $170^{\circ} \mathrm{C}$ for $7 \mathrm{~h}(2)$ and after storage for 1 month in air (3); (BiO)HCOO treated with EG at $190^{\circ} \mathrm{C}$ for $7 \mathrm{~h} \mathrm{(4).}$

Thus, when $(\mathrm{BiO}) \mathrm{HCOO}$ was treated at $\mathrm{T}=(170 \pm 2)^{\circ} \mathrm{C}$ for $7 \mathrm{~h}$, the corresponding $(\mathrm{BiO}) \mathrm{HCOO}$ reflexes disappear with the appearance of individual reflexes of a phase different from the initial one. According to the chemical analysis, the Bi content in the sample was $65.6 \mathrm{wt} . \%$, which was very close to the values determined for the compound of the composition $\mathrm{Bi}_{2}\left(\mathrm{OCH}_{2} \mathrm{CH}_{2} \mathrm{O}\right)_{3}(66.8 \mathrm{wt} . \%)$ [22]. When stored in air for one month or washed with water, the resulting compound was completely converted to $(\mathrm{BiO})_{2} \mathrm{CO}_{3}$ according to equation (2).

$$
2 \mathrm{Bi}_{2}\left(\mathrm{OCH}_{2} \mathrm{CH}_{2} \mathrm{O}\right)_{3}+15 \mathrm{O}_{2} \rightarrow 2(\mathrm{BiO})_{2} \mathrm{CO}_{3}+10 \mathrm{CO}_{2}+12 \mathrm{H}_{2} \mathrm{O}
$$

In the case of heat treatment of bismuth formates in EG, at a temperature close to the boiling point, bismuth was reduced to metal (ICDD 46-1246). The reaction of bismuth formates reduction by glycolaldehyde to metal proceeds according to equations (3) and (4).

$$
\begin{aligned}
& \mathrm{HOCH} \mathrm{CHO}_{2} \mathrm{CHO}(\mathrm{BiO}) \mathrm{HCOO} \rightarrow 2 \mathrm{Bi}+\mathrm{HOCH}_{2} \mathrm{COOH}+2 \mathrm{CO}_{2}+\mathrm{H}_{2} \mathrm{O} \\
& \mathrm{HOCH}_{2} \mathrm{CHO}+2 \mathrm{Bi}(\mathrm{HCOO})_{3}+2 \mathrm{O}_{2} \rightarrow 2 \mathrm{Bi}+\mathrm{HOCH}_{2} \mathrm{COOH}+6 \mathrm{CO}_{2}+3 \mathrm{H}_{2} \mathrm{O}
\end{aligned}
$$

It should be noted that the complete reduction of bismuth at $\mathrm{T}=190^{\circ} \mathrm{C}$ occurred with a processing time of at least $7 \mathrm{~h}$. Apparently, the amount of oxidized EG is not sufficient for the reduction of all metal ions, and in parallel, there was the formation of a more stable compound $-\mathrm{Bi}_{2}\left(\mathrm{OCH}_{2} \mathrm{CH}_{2} \mathrm{O}\right)_{3}$, for the decomposition of which either a higher temperature or an increase in the heat treatment time with a constant temperature of $190^{\circ} \mathrm{C}$ was required. During the synthesis process, this compound is reduced by glycolaldehyde to metallic bismuth at a temperature of $190^{\circ} \mathrm{C}$ and a processing time of at least 7 hours by the equation:

$$
\mathrm{Bi}_{2}\left(\mathrm{OCH}_{2} \mathrm{CH}_{2} \mathrm{O}\right)_{3}+\mathrm{HOCH}_{2} \mathrm{CH}_{2} \mathrm{HO}+7 \mathrm{O}_{2} \rightarrow 2 \mathrm{Bi}+6 \mathrm{CO}_{2}+7 \mathrm{H}_{2} \mathrm{O}+\mathrm{HOCH}_{2} \mathrm{COOH}_{(5)}
$$

According to the SEM images (Fig. 2), thermal exposure to bismuth formates in the EG at $\mathrm{T}=170^{\circ} \mathrm{C}$ for $7 \mathrm{~h}$ were produced $\mathrm{Bi}_{2}\left(\mathrm{OCH}_{2} \mathrm{CH}_{2} \mathrm{O}\right)_{3}$ particles with an elongated prismatic 
shape of 100-150 $\mu \mathrm{m}$ and a thickness of $20-40 \mu \mathrm{m}$. With an increase in temperature to $195^{\circ} \mathrm{C}$ and stirring for $4 \mathrm{~h}$, the structural layers were split to form particles of $0.5 \mu \mathrm{m}$. With an increase in the heat treatment time to $7 \mathrm{~h}$, the $\mathrm{Bi}_{2}\left(\mathrm{OCH}_{2} \mathrm{CH}_{2} \mathrm{O}\right)_{3}$ was reduced to a metal with a particle size of 150-250 $\mathrm{nm}$. Submicron-sized Bi particles were obtained from $\mathrm{Bi}(\mathrm{HCOO})_{3}$ when it was added to the preheated $\mathrm{EG}$ to $\mathrm{T}=195^{\circ} \mathrm{C}$ and stirred for $7 \mathrm{~h}$.
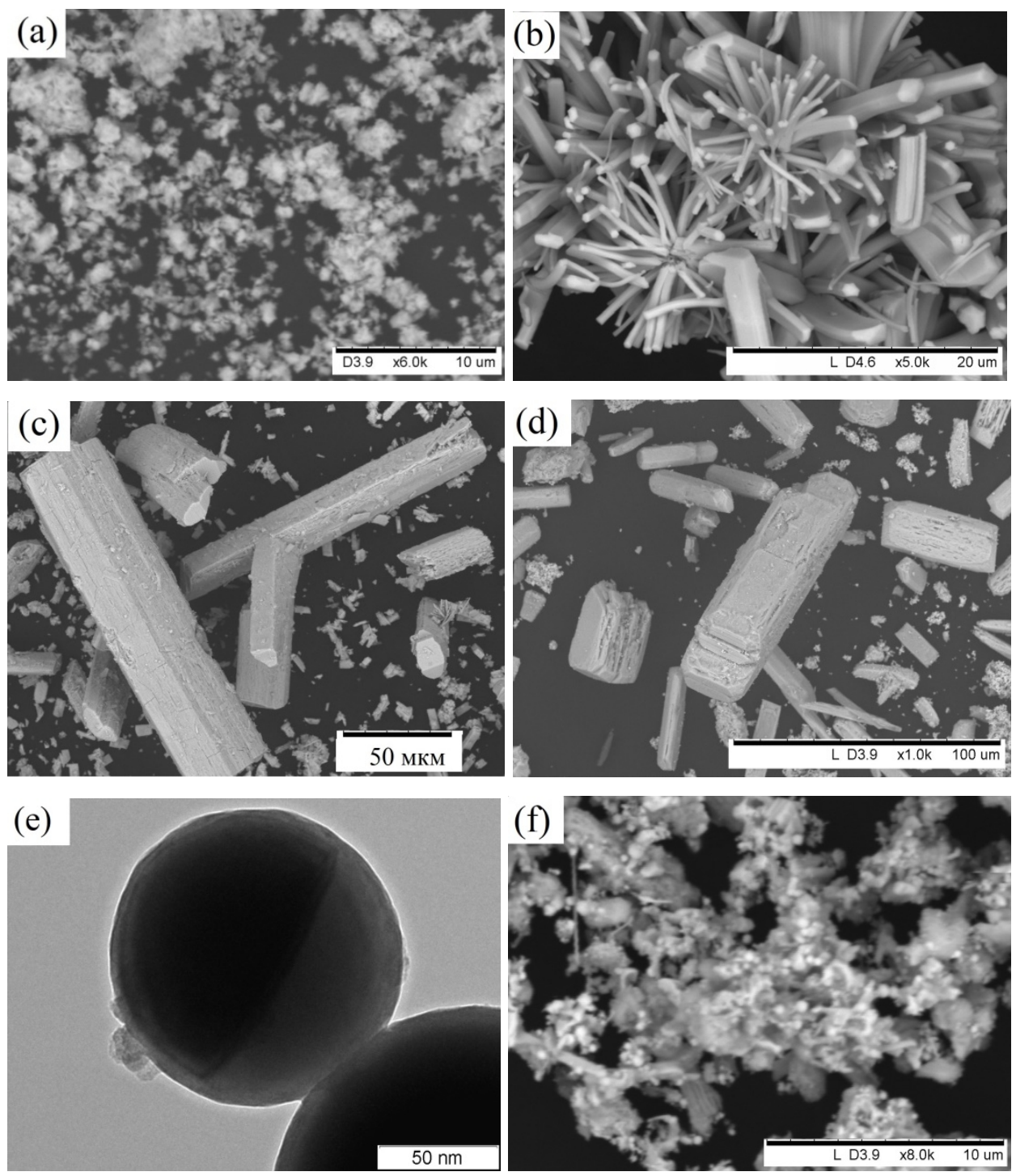

Fig. 2. SEM images of $(\mathrm{BiO}) \mathrm{HCOO}(\mathrm{a}) \mathrm{Bi}(\mathrm{HCOO})_{3}(\mathrm{~b}),(\mathrm{BiO}) \mathrm{HCOO}$ heated in $\mathrm{EG}$ at $170^{\circ} \mathrm{C}$ for $7 \mathrm{~h}$ (c), at $190^{\circ} \mathrm{C}-4 \mathrm{~h}(\mathrm{~d})$ and HRTEM of $(\mathrm{BiO}) \mathrm{HCOO}$ heated in $\mathrm{EG}$ at $190^{\circ} \mathrm{C}$ for $7 \mathrm{~h}$ (e) and $\mathrm{Bi}(\mathrm{HCOO})_{3}$ heated in $\mathrm{EG}$ at $190^{\circ} \mathrm{C}$ for $7 \mathrm{~h}(\mathrm{f})$.

It is known that $\mathrm{Bi}^{3+}$ has a $6 \mathrm{~s}^{2}$ unshared pair of electrons and a $6 \mathrm{p}^{0}$ free orbital, as well as orbitals $5 \mathrm{f}^{0}$ and $6 \mathrm{~d}^{0}$, and therefore, the formation of compounds with different coordination numbers occurs in the solution [23]. Polyols such as EG can act as complexing agents for various metal ions because of the presence of OH-groups in their composition. It 
is well known the bismuth does not form anionic complexes with perchlorate ions and exists in chloric acid solutions in the form of $\left[\mathrm{Bi}\left(\mathrm{H}_{2} \mathrm{O}\right)_{6}\right]^{3+}$. Therefore to study the complexes of bismuth with ethylene glycol, solutions of bismuth in chloric acid were used. The concentration of $\left[\mathrm{H}^{+}\right]$should be at least $1 \mathrm{~mol} \mathrm{~L}^{-1}[24]$. At $\mathrm{pH}=0$, about $4 \%$ of bismuth is in the form of $\mathrm{Bi}(\mathrm{OH})^{2+}$, and at $\mathrm{pH}=4-12$, it is in the form of $\mathrm{Bi}(\mathrm{OH})_{3}$. Uv-vis absorption spectra of bismuth chloric acid solutions indicate that bismuth complexation occurred when EG was added at different concentrations (Fig. 3).

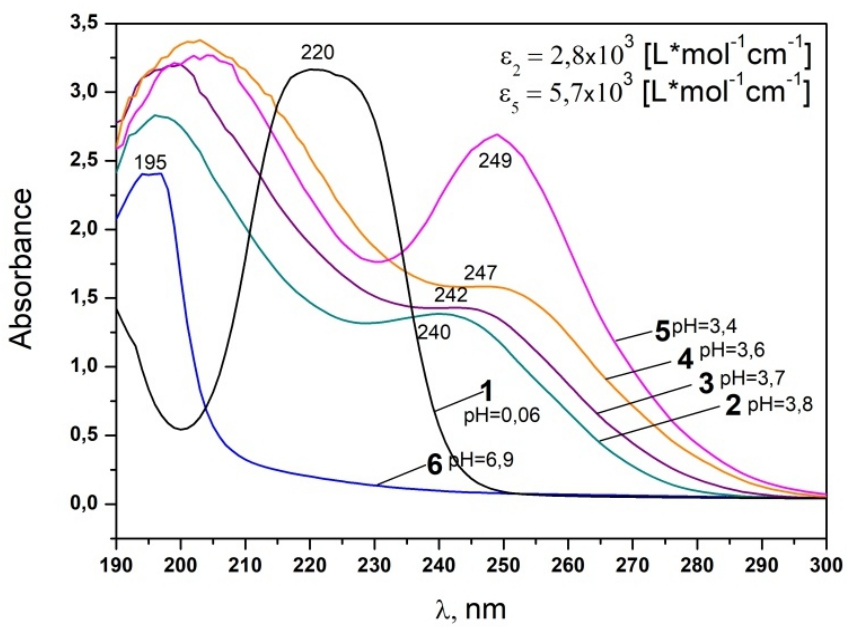

Fig. 3. Uv-vis absorption spectra of bismuth-containing solutions $1.16 \mathrm{M} \mathrm{HClO}_{4}(1)$ and $0.12 \mathrm{M}$ $\mathrm{HClO}_{4}(2)$ in the presence of EG with a concentration of $1.8 \mathrm{M}(3), 9.1 \mathrm{M}(4), 18.1 \mathrm{M}(5), 18.3 \mathrm{M}(6)$. The concentration of bismuth is $1.03 \cdot 10^{-4} \mathrm{M}(2-5)$.

In the EG spectrum, the $195 \mathrm{~nm}$ band corresponds to the $\mathrm{n} \rightarrow \sigma^{*}(\mathrm{C}-\mathrm{O})$ transition. The absorption band with a maximum at $220 \mathrm{~nm}$ of bismuth solution in chloric acid with $\mathrm{pH}=$ 0.06 corresponds to the absorption of $\mathrm{Bi}^{3+}$. When water was added to the bismuth solution, the absorption band of the bismuth cation disappears with the appearance of the absorption maximum at $240 \mathrm{~nm}$, which is characteristic of the electron transition from HOMO to LUMO in $\mathrm{Bi}(\mathrm{OH})_{3}$. When EG was added to the solution, a bathochromic band shift occurred, which indicated electronic transition and the appearance of lower-energy orbitals. With an increase in the EG concentration, a bathochromic shift of the absorption maximum to $249 \mathrm{~nm}$ occurred, with a hyperchromic increase in the extinction coefficient $(\varepsilon)$ from $2.8 \cdot 10^{3}$ to $5.7 \cdot 10^{3}\left(\mathrm{~L} \mathrm{~mol}^{-1} \mathrm{~cm}^{-1}\right)$. From the different types of curves on the absorption spectra of bismuth-containing solutions, it follows that this is not the only complex compound of bismuth with EG. This can be explained by the gradual replacement of $\mathrm{OH}$ groups with ethylene glycol molecules.

Studies of the thermal stability of bismuth formates in EG have shown that the gradual heating of the reaction mixture at the first stage leads to the formation of bismuth complexes with ethylene glycol. So, at a temperature of $23^{\circ} \mathrm{C}$, the content of bismuth in the solution is $0.006 \mathrm{~g} \cdot \mathrm{L}^{-1}$, and when the temperature rises to $60^{\circ} \mathrm{C}$, its content increases to $0.018 \mathrm{~g} \cdot \mathrm{L}^{-1}$. Such complexes can be formed into highly condensed compounds by intramolecular interactions [25], which lead to the formation of chain polymers with a high molecular weight in the system. The reaction of such complex formation can be represented according to schemes (6) and (7).

$$
\begin{aligned}
& 2(\mathrm{BiO}) \mathrm{HCOO}+3 \mathrm{HOCH}_{2} \mathrm{CH}_{2} \mathrm{OH} \rightarrow \mathrm{Bi}_{2}\left(\mathrm{OCH}_{2} \mathrm{CH}_{2} \mathrm{O}\right)_{3}+2 \mathrm{HCOOH}+\mathrm{H}_{2} \mathrm{O} \\
& \mathrm{nBi}_{2}\left(\mathrm{OCH}_{2} \mathrm{CH}_{2} \mathrm{O}\right)_{3} \rightarrow\left[\mathrm{Bi}_{2}\left(\mathrm{OCH}_{2} \mathrm{CH}_{2} \mathrm{O}\right)_{3}\right]_{\mathrm{n}}
\end{aligned}
$$


Thus, (BiO)HCOO was dissolved in the EG to form stable glycolate complexes that prevented the deposition of metallic Bi particles. According to the mechanism described above, when the solution of $(\mathrm{BiO}) \mathrm{HCOO}$ in $\mathrm{EG}$ was gradually heated to $170^{\circ} \mathrm{C}$, the formation of $\mathrm{Bi}_{2}\left(\mathrm{OCH}_{2} \mathrm{CH}_{2} \mathrm{O}\right)_{3}$ occurred. Then, when the temperature rose to $190^{\circ} \mathrm{C}$, the excess of $\mathrm{EG}$ in the solution was oxidized to $\mathrm{HOCH}_{2} \mathrm{CHO}$ which subsequently reduced the $\mathrm{Bi}_{2}\left(\mathrm{OCH}_{2} \mathrm{CH}_{2} \mathrm{O}\right)_{3}$ to metallic bismuth.

The IR spectrum of bismuth glycolate (Fig. 4) obtained from (BiO) $\mathrm{HCOO}$ at $170^{\circ} \mathrm{C}$ is compared with the spectra for EG, aluminum and titanium glycolate [26, 27].

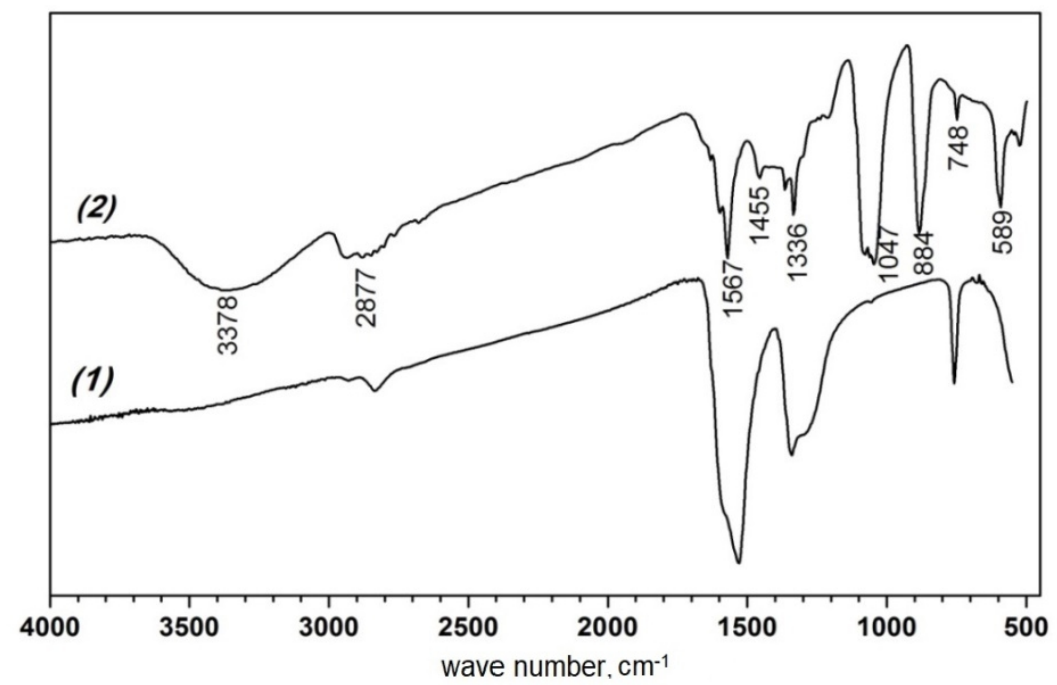

Fig. 4. IR spectra of as-synthesized (BiO)HCOO (1) heated in EG at $170^{\circ} \mathrm{C}$ for $7 \mathrm{~h}(2)$.

TG, mass. $\%$

Ionic current, A $10^{-12}$

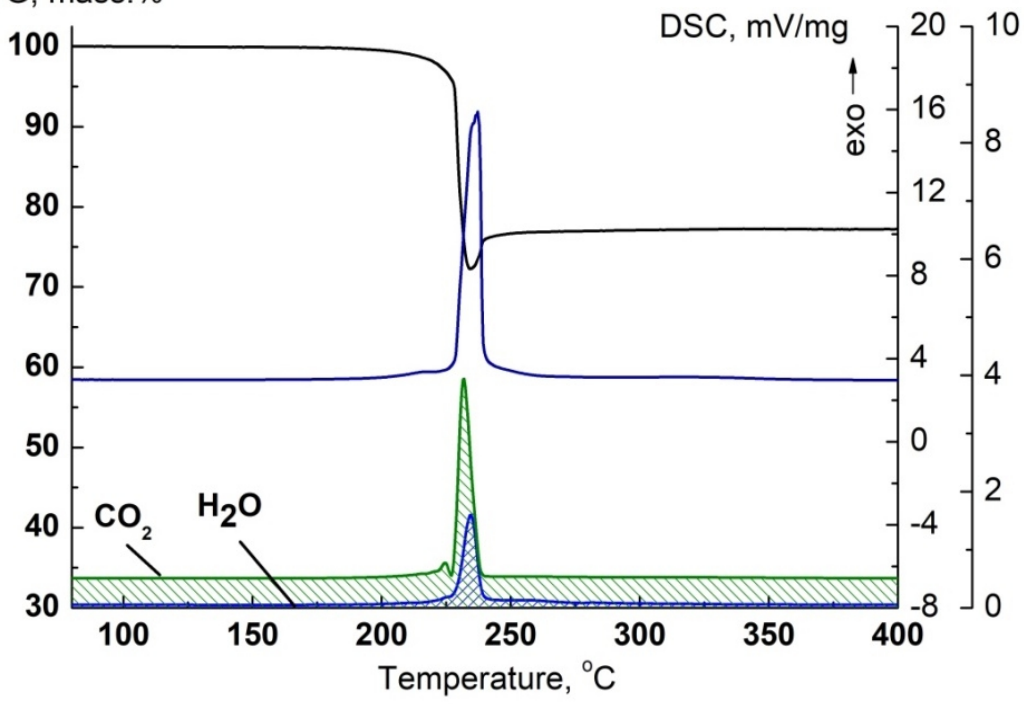

Fig. 5. TG-DSC curves of $\mathrm{Bi}_{2}\left(\mathrm{OCH}_{2} \mathrm{CH}_{2} \mathrm{O}\right)_{3}$ linear heating and mass spectra of $\mathrm{H}_{2} \mathrm{O}$ and $\mathrm{CO}_{2}$. 
The bands of symmetric and asymmetric valence vibrations of the carboxyl group (COO-) of (BiO)HCOO disappeared, while the bands of valence vibrations of the $(\mathrm{C}-\mathrm{O})$ and (Bi-O) bonds appeared at $1047 \mathrm{~cm}^{-1}$ and $589 \mathrm{~cm}^{-1}$, correspondingly. The wide absorption band in the region of 3300-3500 $\mathrm{cm}^{-1}$ and the medium intensity band at 1587 $\mathrm{cm}^{-1}$ referred to the valence and deformation vibrations of the $\mathrm{O}-\mathrm{H}$ bond, forming intermolecular hydrogen bonds. The decrease in the bands intensity of the valence 2943$2676 \mathrm{~cm}^{-1}$ and deformation $1205-1455 \mathrm{~cm}^{-1}$ vibrations of the $\mathrm{C}-\mathrm{H}$ bond compared to the $\mathrm{C}$ $\mathrm{H}$ vibrations in the EG indicated that the mobility of the glycolate ion in $\mathrm{Bi}_{2}\left(\mathrm{OCH}_{2} \mathrm{CH}_{2} \mathrm{O}\right)_{3}$ was limited.

As seen from Fig. 5, the decomposition of $\mathrm{Bi}_{2}\left(\mathrm{OCH}_{2} \mathrm{CH}_{2} \mathrm{O}\right)_{3}$ begins at $\mathrm{T}=190^{\circ} \mathrm{C}$ with a steep drop in mass on the TG and a maximum velocity at $235^{\circ} \mathrm{C}$ on the DSC curve. Metal oxidation occurs with a slight increase in mass to a temperature of $260^{\circ} \mathrm{C}$.

On the mass spectra of the gaseous reaction products, an increase in the ionic current of $\mathrm{H}_{2} \mathrm{O}$ and $\mathrm{CO}_{2}$ is recorded, the slow tail of which extends up to $\mathrm{T}=370^{\circ} \mathrm{C}$. The final mass change corresponds to a value of $22.6 \mathrm{wt} . \%\left(\Delta \mathrm{m}_{\mathrm{t}}=22.07 \mathrm{wt} . \%\right)$. Therefore, on the basis of the above thermolysis results of $\mathrm{Bi}_{2}\left(\mathrm{OCH}_{2} \mathrm{CH}_{2} \mathrm{O}\right)_{3}$ in air, it is possible to present the equation of decomposition to bismuth oxide of monoclinic modification according to a reaction $(8)$.

$$
2 \mathrm{Bi}_{2}\left(\mathrm{OCH}_{2} \mathrm{CH}_{2} \mathrm{O}\right)_{3}+15 \mathrm{O}_{2} \rightarrow 2 \mathrm{Bi}_{2} \mathrm{O}_{3}+12 \mathrm{CO}_{2}+12 \mathrm{H}_{2} \mathrm{O}
$$

\section{Conclusion}

In the present work, the study of metallic bismuth powders preparation by thermal decomposition bismuth formates in ethylene glycol medium was conducted. The dissolution of bismuth formates in EG at elevated temperatures is accompanied by the formation of stable glycolate complexes. It was found that the gradual heating of the reaction mixture to a temperature of $100-150^{\circ} \mathrm{C}$ leads to the formation of an intermediate compound - bismuth glycolate. When the temperature rises to $170^{\circ} \mathrm{C}$, glycolaldehyde converts bismuth from bismuth glycolate into spherical metal particles with a size of 100 $150 \mathrm{~nm}$. The decomposition of bismuth glycolate at a temperature of $190^{\circ} \mathrm{C}$ in air goes through the formation of metallic bismuth. With a further increase in temperature to $370^{\circ} \mathrm{C}$, bismuth is oxidized to monoclinic bismuth oxide.

The research was funded within the state assignment to ISSCM SB RAS (Project No. FWUS-20210009).

\section{References}

1. W.J. Tomlinson, I. Collier, J. Mater. Sci. 22, 1835 (1987)

2. J. Eickmans, L. Leenders, J. Lamotte, K. Dierksen, W. Jacobsen. Circuit World, 22, 26 (1996)

3. Z.B. Zhang, X.Y. Sun, M.S. Dresselhaus, J.Y. Ying, J. Heremans, Phys. Rev. B 61, 4850 (1999)

4. S. Murakami, Phys. Rev. Lett. 97, 236805 (2006)

5. J. Heremans, T.M. Thrush, Phys. Rev. B 59, 12579 (1999)

6. E.A. Sedov, K.P. Riikonen, K.Yu. Arutyunov, Quant. Mater. 2, id 18 (2017)

7. E.E. Foos, R.M. Stroud, A.D. Berry, A.W. Snow, J.P. Armistead, J. Am. Chem. Soc. 122, $7114(2000)$ 
8. D. Ma, J. Zhao, Y. Zhao, X. Hao, L. Li, L. Zhang, Y. Lu, C. Yu, Colloids Surf. A Physicochem, Eng. Asp. 395, 276 (2012)

9. M. Motoyama, Y. Fukunaka, S. Kikuchi, Electrochim. Acta 51, 897 (2005)

10. L. Kumari, J.H. Lin, Y.R. Ma, Nanotech. 18, 295605 (2007)

11. J. Wu, H. Yang, H. Li, Z. Lu, X. Yu, R. Chen, J. Alloys Compd. 498, L8 (2010)

12. C. Goia, E. Matijević, D.V. Goia, J. Mater. Res. 20, 1507 (2005)

13. A.Yu. Olenin, G.V. Lisichkin, Russ. Chem. Rev. 80, 605 (2011)

14. G. Cheng, J. Wu, F. Xiao, H. Yu, Z. Lu, X. Yu, R. Chen, Mater. Lett. 63, 2239 (2009)

15. Z. Wang, C. Jiang, R. Huang, H. Peng, X.Tang, J. Phys. Chem. C. 118, 1155 (2014)

16. Y. Gao, H. Niu, C. Zeng, Q. Chen, Chem. Phys. Lett. 367, 141 (2003)

17. S.E. Skrabalak, B.J. Wiley, M.H. Kim, E. Formo, Y. Xia, Nano Lett. 8, 2077 (2008)

18. E.V. Panfilova, B.N. Khlebtsov, A.M. Burov, N.G. Khlebtsov, Colloid J. 74, 99 (2012)

19. J. Li, H. Fan, J. Chen, L. Liu, Colloids Surf. A Physicochem. Eng. Asp. 340, 66 (2009)

20. J. Wu, F. Qin, Z. Lu, H.J. Yang, R. Chen, Nanoscale Res. Lett. 6, 66 (2011)

21. G. Cheng. J. Wu, F. Xiao, H. Yu, Z. Lu, X. Yu, R. Chen, Mater. Lett. 63, 2239 (2009)

22. B.A. Cloutt, D.S. Sagatys, G. Smith, R.C. Bott, Aust. J. Chem. 50, 947 (1997)

23. M. Mehring. Coord. Chem. Rev. 251, 974 (2007)

24. S.B. Erenburg, S. Trubina, Yu.M. Yukhin, M.R. Sharafutdinov, 66, 94 (2017)

25. X. Xiao, R. Hu, C. Liu, C. Xing, C. Qian, X. Zuo, J. Nan, L. Wang, Appl. Catal. B Environ. 140- 141, 433 (2013)

26. B. Xiao, L.P. Wang, R.H. Mei, G.Y. Wang, Chinese Chem. Lett. 22, 741 (2011)

27. V.N. Krasil'nikov, A.P. Shtin, O.I. Gyrdasova, E.V. Polyakov, G.P. Shveikin, Russ. J. Inorg. Chem. 53, 1065 (2008) 